OPEN ACCESS

Edited by:

Jian Zhao,

Shanghai University of Electric Power,

China

Reviewed by:

Haoxi Cong,

North China Electric Power University,

China

Li Zhang,

Shandong University, China

Changyun $\mathrm{Li}$,

Shandong University of Science and

Technology, China

*Correspondence:

Jianlan Yang

Yangiianlan@hnu.edu.cn

Specialty section:

This article was submitted to

Process and Energy Systems

Engineering,

a section of the journal

Frontiers in Energy Research

Received: 19 October 2021

Accepted: 10 November 2021

Published: 17 December 2021

Citation:

Pei Z, Ma Y, Wu M and Yang J (2021) Study on Load-Participated Demand

Response Model Based on

Load Aggregator.

Front. Energy Res. 9:797979.

doi: 10.3389/fenrg.2021.797979

\section{Study on Load-Participated Demand Response Model Based on Load Aggregator}

\author{
Zixia Pei ${ }^{1}$, Yunlong $\mathrm{Ma}^{2}$, Mengyun $\mathrm{Wu}^{3}$ and Jianlan Yang ${ }^{4 *}$ \\ ${ }^{1}$ State Grid Jiangsu Electric Power Co., Ltd, Yancheng Power Supply Branch, Yancheng, China, ${ }^{2}$ State Grid Jiangsu Electric \\ Power Co., Ltd., Nanjing, China, ${ }^{3}$ State Grid Jiangsu Electric Power Co., Ltd, Wuxi Power Supply Branch, Wuxi, China, ${ }^{4}$ College \\ of Electrical and Information Engineering, Hunan University, Changsha, China
}

In the reform of the electricity market, along with the gradual opening of the electricity sales side as well as the increase in the proportion of residential electricity consumption, the user load of the demand side has become an essential resource for demand response (DR). To efficiently utilize the residential load resources, new market participants, such as load aggregator (LA) have emerged. First, the basic concept of load aggregator is introduced in this paper, the origin and definition of LA is studied, and the classification of aggregated resources and the current situation of $L A$ operation in some countries are presented. Then the article analyzes the market operation mode of $L A$ and the uncertainty of $L A$ in operation in detail, including the LA service on the user side, transaction mode and hierarchical structure associated with the operation, the uncertainty classification analysis, and associated strategies to address the problem. The LA load integration method and the scheduling control strategy are discussed. Finally, suggestions and ideas on the future research direction are proposed.

Keywords: load aggregator, demand response model, residential load, uncertainty, control strategy

\section{INTRODUCTION}

Although China has made amazing achievements in the development of the power grid and energy construction, there is still an imbalance between power supply and load demand, and some regions still face great challenge in load regulation during the peak load period (Luo et al., 2021; Sun et al., 2022). The development and application of new energy have eased the pressure of electricity consumption to some extent, but the randomness and volatility of its existence pose a high requirement for the system of integrating more new energy. Consequently, the role of demandside resources in maintaining a balanced power supply and load demand has a great significance (Zeng et al., 2016).

Demand response (DR) is an effective method for load control in smart grid. The implementation of the DR project has a great economic benefit and achieved good results. However, the small capacity of residential loads, the high degree of fragmentation, and the difficulty of control lead to obstacles in scheduling small-scale load resources in the system (Li et al., 2017). In order to effectively utilize the scheduling potential of these dispersed demand-side resources, load aggregator (LA) has emerged in developed countries, which is able to explore load resources with response value through professional technical means (Gao et al., 2013; Zhang, 2015). LA aggregates dispatchable customer load resources within a certain range and participates in grid dispatch as a whole, increasing the opportunity for demand-side participation in the market. The emergence of LA enhances the 
competitiveness of residential consumers in the DR market and also provides more high-quality DR resources for the power market. In addition, the emergency and development of LA has contributed to the stable, economic, and efficient operation of the power system (Bandyopadhyay et al., 2011; Sun et al., 2020).

LA, as a new DR commercial electricity model, has carried out relevant theoretical research and practice earlier. Domestic research started late, but with the gradual opening of electricity sales side and the popularization of intelligent household appliances, the demand-side residential load resources have become an influential resource for DR, and the domestic research on the LA-based residential load participation DR model is also in progress. This paper first analyzes the basic concept of LA and the current situation of operation at home and abroad. Second, the paper focuses on the market operation mode of LA and the uncertainty problems in operation, including the various businesses of LA on the user side, the two transaction modes of bidding in the operation-related market and signing bilateral contracts, the layered participation structure of LA in the market, the classification analysis of uncertainty problems, and coping strategies. Then the information prediction, load integration method, and scheduling control strategy of LA are studied in detail. Finally, suggestions and ideas for future research based on LA participation in DR mode are proposed.

\section{INTRODUCTION TO LOAD AGGREGATOR}

\subsection{History of load aggregator}

\subsubsection{Concept of load aggregator}

A load-serving entity (LSE) is an organization connecting the electricity market and consumers (Jin et al., 2019). In the early days, LSE is mainly engaged in the business of buying and selling electricity, and it is the predecessor of LA. As the utilization of demand-side resources intensified, LA developed from a subdivision of LSE to a more specialized DR resource integration organization (Saad et al., 2009). Burger et al. (2017) defines aggregation as the grouping of different agents in the power system, such as consumers and producers or consumers with other combinations, to participate as a single entity in the power system market or sell services to system operators. To sum up, LA is an integrator of DR resources. LA acts as a bridge between power users and service purchasers, integrating and managing customer-side load resources, while also acting as a communication entity between grid companies and power users, making effective use of idle and scattered load resources.

\subsubsection{Classification of load aggregator control resource}

LA control resource types can be divided into three categories: controllable load, distributed power source, and energy storage device.

1) Controllable load. Loads with dispatchable potential are divided into transferable load, reducible load, and thermostatically controlled loads. Transferable load refers to the load with constant electricity consumption during the scheduling cycle and relatively flexible start-up time (Qi et al., 2020). Reducible load refers to the load with certain flexibility and controllability in working time and power demand, which can change its state according to system demand and is characterized by flexible scheduling, quick response, and small aggregation capacity. Thermostatically controlled loads usually include air conditioning, water heater, and other loads, which are characterized by rapid response, energy storage, and high controllability.

2) Distributed generation. Distributed generation is defined as an independent energy supply system distributed at the user side (Qian, 2019). The extensive application of renewable energy on the user side increases the scheduling control range of the system, allowing the customer side to consume power while also acting as the supply to deliver power to the grid. There are many kinds of distributed generation sources with different characteristics. For example, photovoltaic power generation can only be generated in the daytime, whereas wind power has the function of regulating peak load.

3) Energy storage system. The renewable energy power generation is increasingly popular in China. However, renewable energy is characterized by randomness, intermittency, and volatility (Shu et al., 2017). Energy storage system can improve the supply stability of DR resources and reduce the operational risk of LA, so energy storage systems also become a high-quality resource for LA to maintain energy balance. The classification of energy storage system is shown in Table 1.

\subsection{State-of-the-art for load aggregator 2.2.1 The United States}

The United States is the first country to study DR technology and has the most LA entities. EnerNOC, Comverge, and Pennsylvania-New Jersey-Maryland Interconnection (PJM) power market all have mature experience in LA operation. EnerNOC mainly focuses on large loads, which sells DR resources to the transmission system operator and treats energy management services as its core business. The control resources of Comverge are mainly residential customers, which treats DR as its core business and sells DR resources to DR resource purchasers, such as power companies, transmission system operators, etc. In the PJM power market, any market member that can provide DR services, including LA, electric distribution company (EDC), and LSE, can act as a curtailment service provider (CSP), aggregating the dispersed DR resources on the customer side and providing load curtailment to DR purchasers such as power companies and power generators.

\subsubsection{Australia}

The load aggregation business of Australian Energy Response company is almost for all types of elastic loads. With DR as its core business, it aggregates and sells DR resources to participate in various DR projects and various markets. Considering the physical constraints of user reduction, the customer is notified of the curtailment scheduling plan developed 1 to $2 \mathrm{~h}$ in advance, and the customer is compensated for DR resources based on the amount of curtailed load from the measurement unit. 
TABLE 1 | Classification of energy storage system.

Energy storage system

Mechanical energy storage

Chemical energy storage

Electromagnetic energy storage

Thermal energy storage

Chemical energy storage

\section{Details}

Energy storage through compressed air and pumped storage

Sodium-sulfur batteries, liquid-flow batteries, lead-acid batteries, and lithium electronic batteries

Superconducting magnetic energy storage and supercapacitor energy storage

Sensible heat storage and latent heat storage

Use of hydrogen or synthetic natural gas as a secondary energy carrier

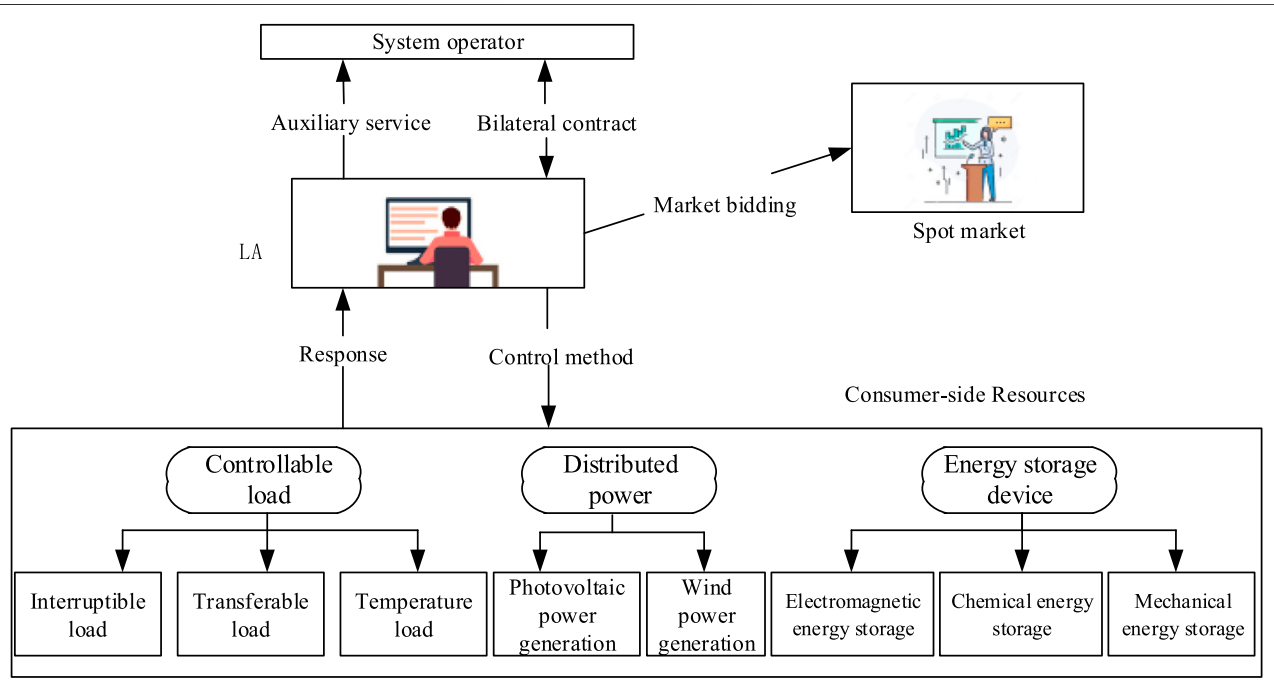

FIGURE 1 | Operational framework of the load aggregator (LA).

\subsubsection{Europe}

Flextricity, a British company, treats electrical power supply and demand control as its core business. It aggregates resources, including small generator, backup power source, and large industrial and commercial users, and sells flexible load reduction resources to various markets. The British company KIMIPower, treating DR resource aggregation as the core obligation, opened the integration business for small consumers in 2014, also aggregates all kinds of distributed generation resources. Voltails, a French company, aggregates the resources of curtailed customers, provides free installation of smart energy measurement and monitoring equipment, and remote control of smart loads. Although Europe has less experience in LA operation than the United States, some experimental projects with the nature of LA have achieved results, such as virtual fuel-cell power plant project and flexible electricity network to integrate the expected energy solution (Wei et al., 2013).

\subsubsection{China}

Since 2012, China has explored and established several Las in some major cities, such as the Nanjing Xinlian Power Cloud Co., Ltd., Suzhou Zhidian Energy Saving Technology Co., Ltd., and Changzhou Jiyuan Energy Technology Co., Ltd. (Zhang, 2001). Xinlian Power Energy Cloud Co., Ltd., as an LA, undertakes the construction of a DR support platform system in the Jiangsu province and responds to a cumulative load of $798,000 \mathrm{~kW}$ in
2016, accounting for $23 \%$ of the response volume in the Jiangsu province.

\section{MARKET OPERATION MODE OF LOAD AGGREGATOR}

DR operation mode of LA can be regarded as an advanced regional centralized management mode of load. Specifically, its operation mode can be comprehensively analyzed from the userside business responsibilities and transaction mode of LA. The operational framework of LA is shown in Figure 1.

\subsection{Responsibility of load aggregator on the user side}

The business of LA on the user side mainly includes intelligent monitoring installation and technical support, user DR potential analysis, incentive mechanism design, and scheduling and planning in advance.

\subsubsection{Intelligent monitoring equipment installation and technical support}

LA is responsible for providing consumers with the installation and maintenance of intelligent monitoring meters and providing technical support, and builds a new type of power supply and 
consumption relationship with real-time interaction between the power grid and the energy flow, information flow, and business flow of the consumer. The user conveys response and electricity consumption measurement information to LA, and LA conveys electricity price signal, incentive signal, temperature, and power control signal to the user. The receiving of information, the control of equipment, and the transmission of data are all carried out based on the installation of intelligent monitoring equipment.

\subsubsection{Analysis of user demand response potential}

LA must study different types of loads and their DR potential, and grasp the magnitude of load elasticity of different electricity-using devices. According to the specific electricity consumption behaviors of the customer (historical data, such as response speed and curtailment), usage habit constraints, and curtailment willingness, specific contracts are developed for customers, to develop the most suitable service for them to arrange their participation in a specific market in order to maximize the use of resources, to maximize the effect and value of $\mathrm{DR}$ participation in the market.

\subsubsection{Incentive mechanism design}

In order to encourage consumers to actively participate in the programs provided by LA, an appropriate incentive mechanism is indispensable. Compensation rates are provided by LA in consultation with the user and are determined according to the specific type of service provided. In order to avoid the unstable operation of the system caused by too many nonresponses of consumers, it is necessary to establish a punishment mechanism to restrain user behavior.

\subsubsection{Scheduling planning in advance}

LA must give full consideration to the satisfaction, power consumption comfort, and power consumption habits of the consumers. LA needs to make scheduling plans in advance and inform consumers in advance. In the formulation of the scheduling plan, LA must comprehensively consider cost reduction, the uncertainty of user default, and satisfy the constraints of user interruption times, minimum cutting duration, and maximum cutting duration, so as to obtain the optimal scheduling combination economically.

\subsection{Transaction methods of load aggregator}

There are two ways of transaction methods: market bidding and bilateral contracts (Chen et al., 2013; Zhang et al., 2015a).

\subsubsection{Market bidding}

LA aggregates a large number of load resources with response potential, competes in market bids on representative of such resources, and accepts scheduling arrangements from market operators (Zhang et al., 2015a). In order to participate in market bidding, LA should predict market price and electricity consumption of customer in advance. Based on the willingness of customer to use electricity and electricity consumption forecast, signs contracts with customers, decides the optimal bidding plan, and participates in market bidding. After winning the bid, LA sends control signals to the user to control the power outage of the user, and the user provides the measurement information of electricity consumption to LA. LA makes a profit from the difference between the electricity revenue generated by the market and the compensation paid to customers. The bidding process is shown in Figure 2.

\subsubsection{Bilateral contracts}

LA provides user-side resources and sells them to the Independent System Operator (ISO), power supply company, power generation company, and other DR resource buyers through bilateral contracts. DR resource purchasers who sign bilateral contracts pay and receive DR load resources. Bilateral transactions are shown in Figure 3. At present, the implementation of DR in China is led by the government and electric power companies, taking the agreement as the carrier, and the market subjects involved are provincial Economic and Information Commission, electric power companies, LAs, and consumers.

To illustrate the DR participation mechanism of LA in China, the Nanjing Xinlian Power Cloud Service Co., Ltd. participated in the 2017 DR of the Jiangsu Province. As shown in Figure 4, it is mainly divided into five stages, as listed in Table 2 .

\subsection{Role of load aggregator in the market}

Energy suppliers, DR regulators, DR service managers, LAs, and power consumers are participants in DR (Li et al., 2015), and their obligatory functions and optimization status are shown in Table 3. The above five DR participants can be divided into three participants, which are the government (DR regulator), power grid company (electric energy supplier and DR service manager), and DR provider (LA and power users).

Figure 5 shows the hierarchical structure of the participating market of LA, including DR resource purchasers, DR market operators, LAs, and consumers. The purchasers of DR resources are ISO, power supply companies, power producers, and other power institutions. The DR market operator is responsible for receiving the $\mathrm{DR}$ quotation and bidding information matching to ensure the maximum matching rate and realize the optimization of market resources. The configuration is equivalent to the market trading center, which can be appointed by the professional department of goverment. LA sets a variety of contract mechanisms to meet the needs of different consumers, so that consumers with different capacities and characteristics can complement the resources of the other.

\section{UNCERTAINTY IN LOAD AGGREGATOR OPERATION}

\subsection{Uncertainty analysis}

Uncertainty mainly includes randomness, fuzziness, incompleteness, instability, and inconsistency, while randomness and fuzziness are the most basic uncertainties ( $\mathrm{Li}$ et al., 2004). Uncertainties in LA operation research can be summarized as boundary uncertainty, parameter uncertainty, behavioral uncertainty, and disturbance, as shown in Figure 6. 


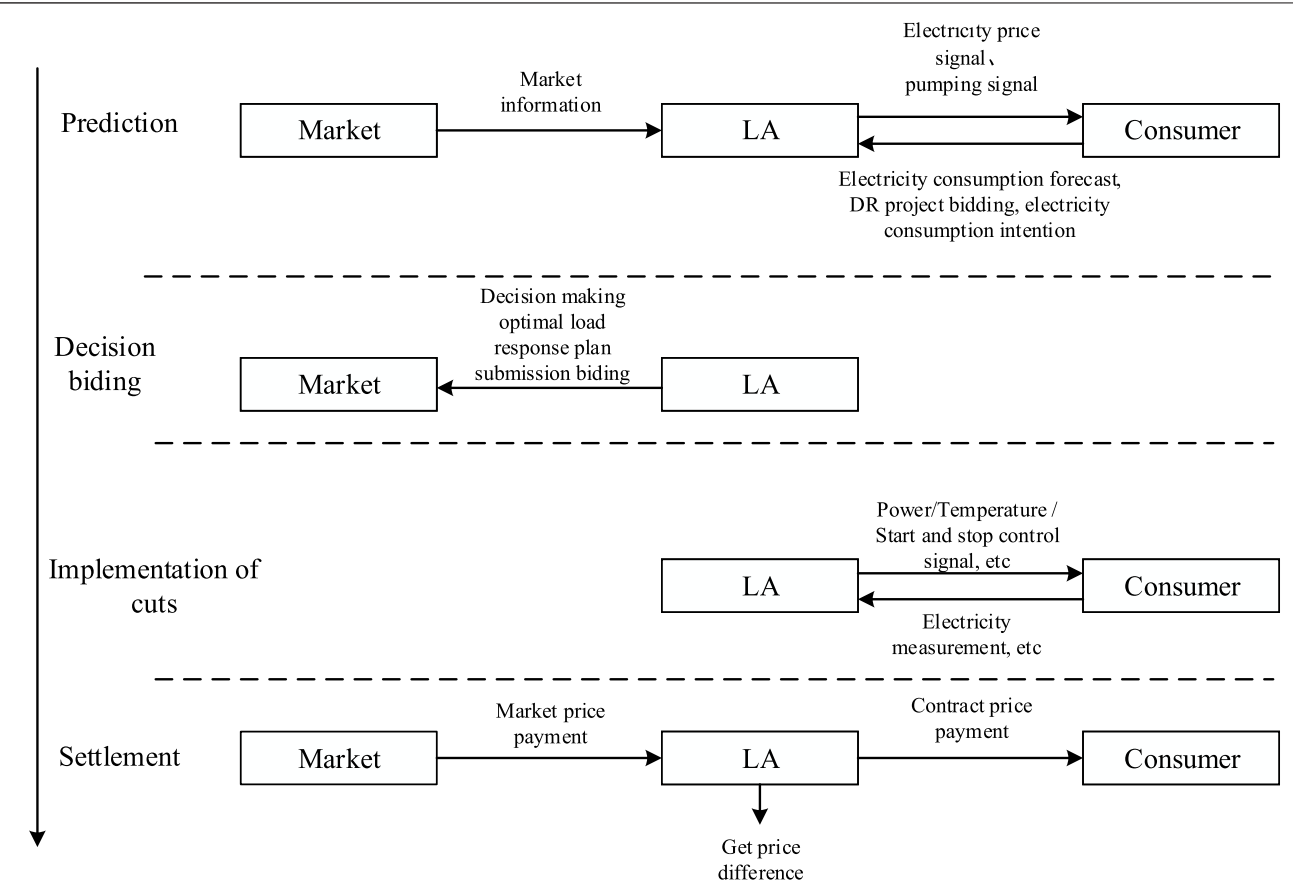

FIGURE 2 | Participation in market bidding.

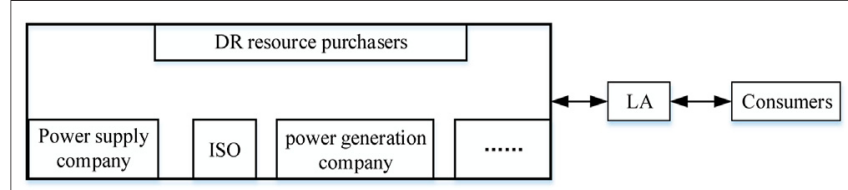

FIGURE 3 | Participating in bilateral transactions.

\subsubsection{Boundary uncertainty}

LA can realize the supply and demand communication of supply and demand information between the grid and customers and is an important carrier for implementing DR and calling demand-side resources, so its operations are involved in the complex environment to identify the boundary uncertainty, such as the market environment, in which the different attitudes of customers toward tariff signals or incentive levels can affect the response behavior of customers. In addition, it also includes the influence of the environment, which includes the policy, economy, and technology.

\subsubsection{Parametric uncertainty}

The parameter uncertainty mainly stems from the input parameters in the decision-making process of the LA operation. Tariff parameters, weather parameters, and customer baseline load all affect the response potential of customers; errors in load forecasting usually have a direct impact on system peak avoidance periods and system capacity shortages.

\subsubsection{Behavioral uncertainty}

Behavioral uncertainty directly affects the operational benefits of LA. Many studies focus on modeling user uncertainty, such as consumer psychology, user response multi-state, normal distribution, etc. (Zhang and Yu, 2018). As far as consumer psychology is concerned, the models commonly used in the current studies are triangular and spindle. Taking the triangular consumer psychology model as an example, as shown in Figure 7, a linear model is adopted to express user response behavior. When given an economic incentive level $x$, the upper and lower bounds of the proportion of user load $i$ are:

$$
\begin{aligned}
\lambda_{i}^{u p}(x) & = \begin{cases}\lambda_{i}^{0}+x \frac{\lambda_{i}^{\text {max }}-\lambda_{i}^{0}}{x_{i}^{\max }}, & 0 \leq x<x_{i}^{\text {max }} \\
\lambda_{i}^{\text {max }}, x \geq x_{i}^{\text {max }}\end{cases} \\
\lambda_{i}^{\text {down }}(x) & =\left\{\begin{array}{l}
\left(x-x_{i}^{0}\right) \frac{\lambda_{i}^{\max }}{x_{i}^{\max }-x_{i}^{0}}, \quad 0 \leq x<x_{i}^{\text {max }} \\
\lambda_{i}^{\max }, x \geq x_{i}^{\text {max }}
\end{array}\right.
\end{aligned}
$$

where $\lambda_{i}^{u p}(x)$ and $\lambda_{i}^{\text {down }}(x)$, respectively, represent the upper and lower bounds of the specific gravity of load cutting. The concepts of other consumer psychology models are shown in Table 4.

\subsubsection{Disturbance}

The disturbance of LA in the response process comes from emergencies, such as communication delay, equipment failure of advanced metering infrastructure (AMI), and malicious network attack (Tabandeh et al., 2016). The development of two-way communication technology, the installation of communication facilities, and advanced metering devices are the prerequisites for effective interaction between LA and customers. AMI is the interface on the user side of DR, and 


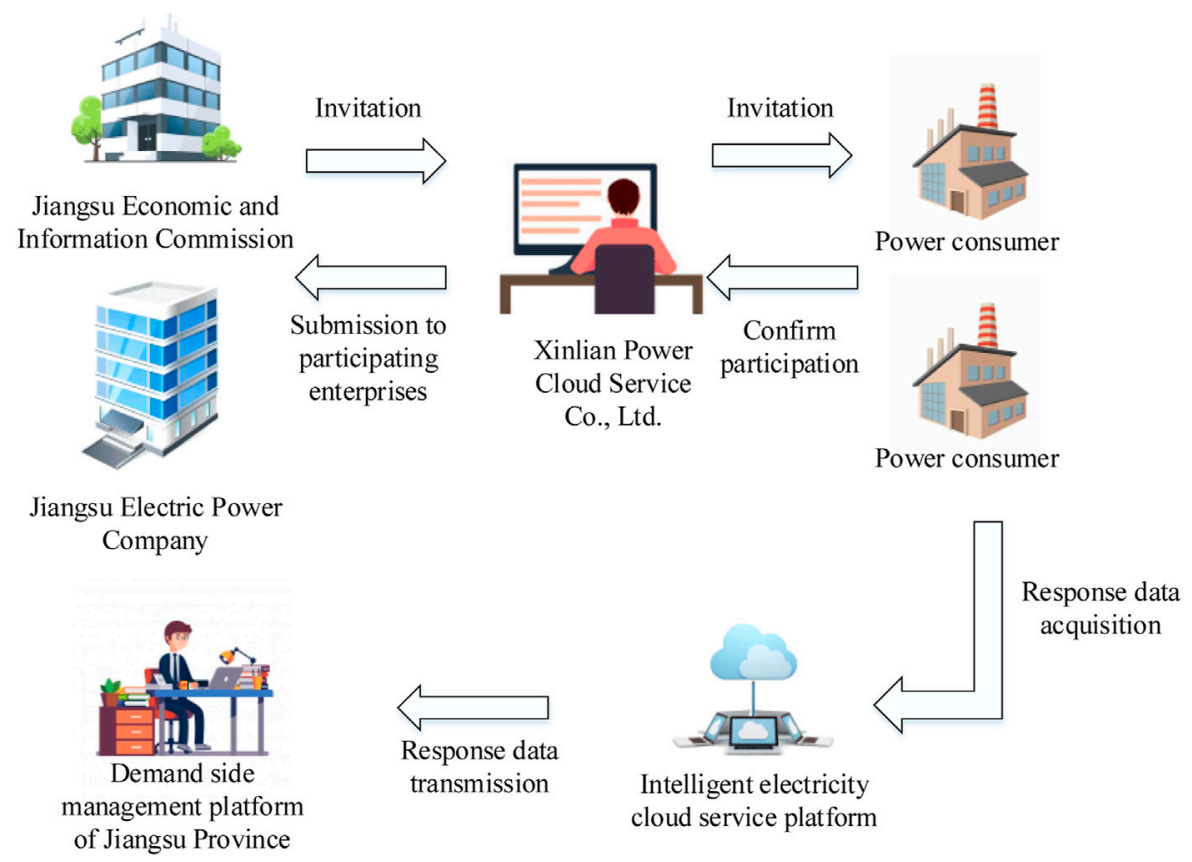

FIGURE 4 | LA participates in the demand response (DR) project instance execution process.

TABLE 2 | Details of the demand response (DR) operation.

Stages

Invitation

Feedback

DR execution

Response settlement

Subsidy distribution
Details

The first stage is invitation. After the DR project is approved, Jiangsu Economic and Information Commission will first send response signals to the load aggregator $(\llcorner A)$, and $L A$ will initiate invitation notices to power consumers

The second stage is the feedback, the user feed backs whether to participate, LA collects the feedback information and submits it to the power company and economic and information technology committee

The third stage is DR execution, in which participating consumers are determined to shut down or lower the load of the electricity equipment at the agreed time. The data of electricity load of consumers will be monitored online by the intelligent electricity cloud service platform and stored in the provincial demand-side management platform

The fourth stage is response settlement, accounting according to user practice response

The fifth stage is subsidy distribution, and the response subsidy is calculated according to the accounting result of the response volume

TABLE 3 | Business functions and optimization status of market entities.

\section{Market entities}

Electricity

customer

LA

Electricity

company

Government

regulator

\section{Business functions}

Load shedding, changes in power consumption behavior, comfort reduction, and compensation

Contacts power companies and customers, participates in market bidding

or bilateral contracts, controls load reduction, and measures and

compensates customers

Reports DR projects and purchases load resources from the market or

bilateral transactions

Approves DR project and sends DR signal to LA

\section{Optimization status}

Trade-off between economy and satisfaction to obtain the optimal reduction strategy

Revenue from sale of DR resources, getting maximization of net income after economic compensation to consumers

Minimize electricity purchase costs its failure will directly affect the implementation effect of DR. Network attack is a factor that cannot be ignored. The control platform of smart home appliances has almost no security protection measures and is more vulnerable to attack than industrial and commercial power control information systems. When the scale of smart home appliances under attack is large enough, the reliability of power supply may be affected (Wu et al., 2018). 


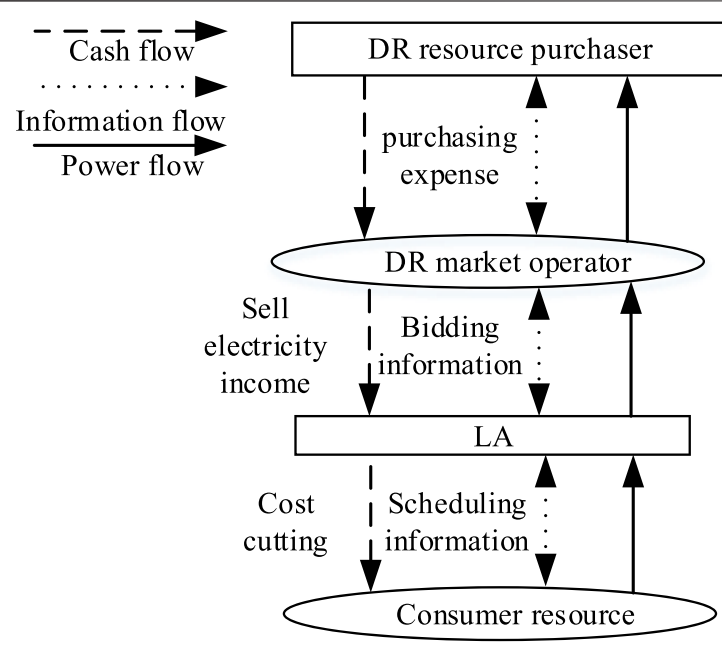

FIGURE 5 | Hierarchical structure of the LA participation market.

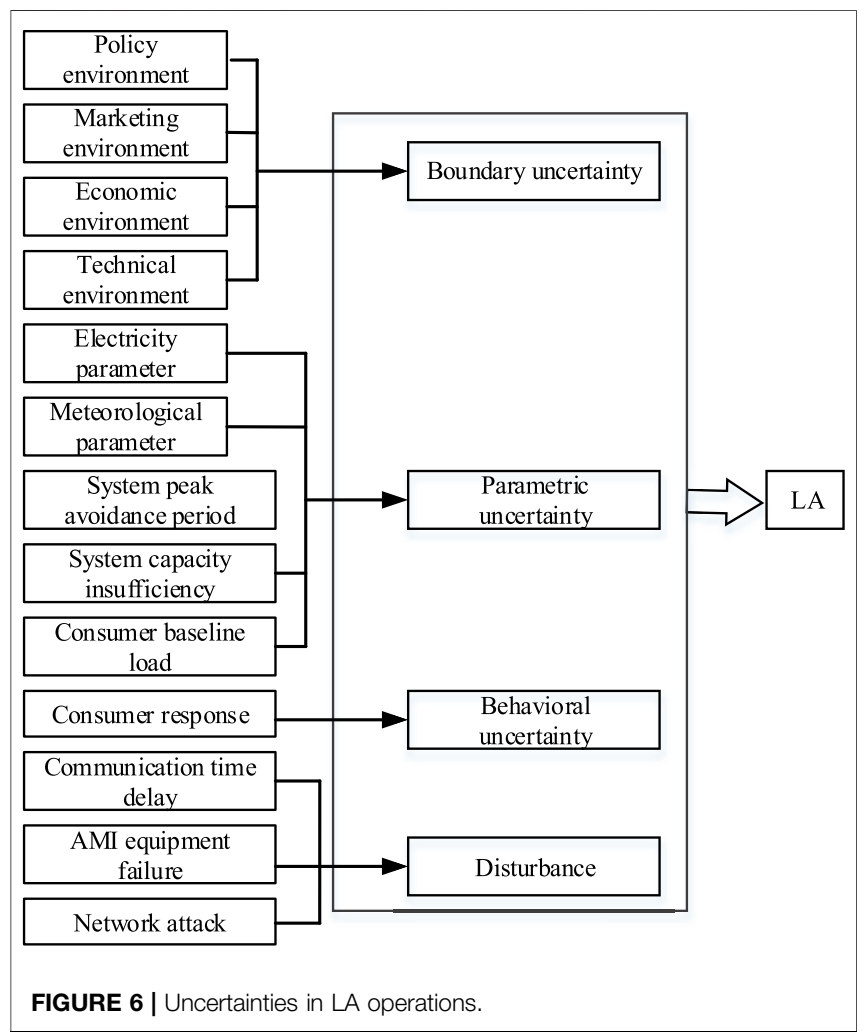

\subsection{Uncertainty response}

When studying LA operation problems with uncertain factors, various analyses and coping strategies can be adopted. Uncertainty analysis methods include sensitivity analysis, multi-scenario analysis, stochastic programming, multiple quasi-optimal solution, and multi-model comparison (Shu et al., 2018). The research of LA mainly focuses on optimization problems, which are usually solved by mathematical programming methods. Considering the

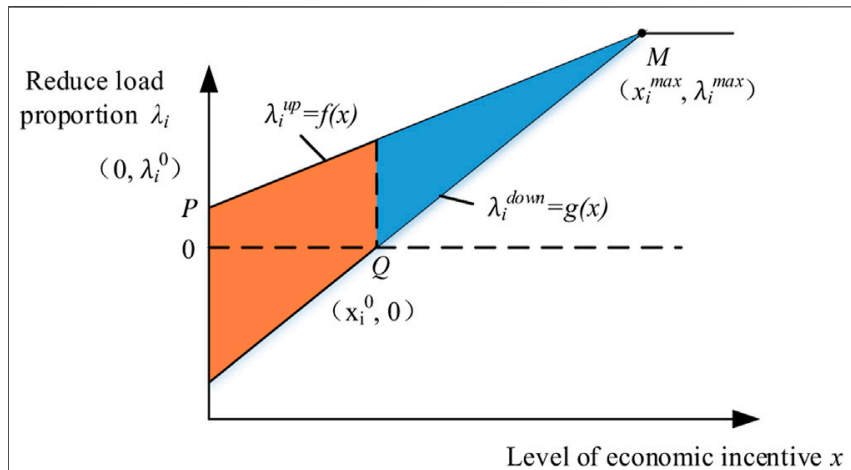

FIGURE 7 | Change trend of user response rate based on consumer psychology model.

uncertainty, the stochastic programming model can be used to model the DR optimization problem according to the stochastic characteristics, fuzzy programming can be used for fuzzy characteristics, and stochastic fuzzy programming method can be further used when both randomness and fuzziness are considered. When there are many uncertain factors in the model, intelligent algorithms, such as artificial bee colony algorithm, genetic algorithm, particle swarm optimization algorithm, dragonfly optimization algorithm, simulated annealing algorithm, and tabu search algorithm, can be considered.

In addition, effective trading mechanism has always been a topic of concern. How to design DR trading mechanism to cope with the uncertainty in LA operation, while taking into account the differentiated interests of the demand side and response side, is the focus of many literature studies. For example, in the Japanese Yokohama Smart City project, a point buyback strategy was carried out to promote active participation of residential customers accordingly (Zhao, 2016).

In response to the situation of the Chinese electricity market, Chen et al. (2013) proposed a power point mechanism. The connotation of power point incentive is to give credit points to consumers for their response behaviors and to motivate consumers by exchanging points for certain electricity service or economic preference, so as to achieve a win-win situation for the power grid, consumers, and LA. The implementation process of obligations includes signing DR project agreement, generating power points, and exchanging power points.

Zhang et al. (2015b) proposed the reward and punishment mechanism for LA to participate in the market, modeled the amount of defaulted capacity of LA aggregate resources to quantify the risk of default, established an energy storage capacity optimization model based on market hierarchical compensation rules, and utilized a certain amount of energy storage capacity to mitigate the uncertainty caused by default of its load. Zhao and Liu (2017) also established a series of reward and punishment mechanisms, including virtual power plant contract breach penalty mechanism, wind and light abandonment penalty mechanism, and interruptible load reward and punishment mechanism. 
TABLE 4 | Concept expression based on consumer psychology model.

Concept

No excitation response

(P-point)

Critical excitation

(Q-point)

Saturation excitation

(M-point)
Implication

Zero incentive level, voluntary user response

Minimum user responsiveness above zero

The user response reaches the ideal value, and the response fluctuation can be almost ignored

\section{Actual background}

Measure the adjustment space that customers have with no change in electricity costs

Based on the maximum possible reduction/transfer cost per unit of electricity when the customer begins to respond

Reflects the maximum effective incentive intensity, which is determined by the marginal response cost when reaching the maximum potential

\section{LOAD INTEGRATION METHOD AND SCHEDULING CONTROL STRATEGY}

\subsection{Information prediction}

Before aggregating these loads to participate in demand response, LA needs to predict the resources it controls, so as to integrate these demand-side resources more effectively. The output prediction of distributed generation will affect the load control decision of LA, and the result of load prediction will often affect the formulation of day-ahead tariffs, and the price trend determines the response of consumers, thus, affecting the load elasticity of consumers.

\subsubsection{Distributed generation}

Wind power generation and photovoltaic power generation are volatile, intermittent, and random, and large-scale access will affect the smooth operation of the power grid (Dong et al., 2016). When LA integrates the distributed generation under its control to participate in the DR, it is necessary to predict the influence of various factors, such as weather on the output of these new energy sources in advance, so as to reduce the loss caused by uncertain factors. The forecasting methods for distributed generation sources can be divided into temporal and spatial scales according to the forecasting scale (Peng et al., 2016). According to different data and methods, the prediction methods can be divided into the following three types: physical method, statistical method, and artificial intelligence.

\subsubsection{Load and electricity prices}

LA carries out load prediction for flexible load and energy storage systems, which can better manage demand-side resources and provide consumers with better service. Short-term load forecasting is most relevant to the operational decisions of LA. Ultrashort-term load forecasting under LA mode is the basis for LA to formulate power generation plans and study DR elasticity (Guo et al., 2021). Different consumers have different reactions to the price of electricity, and residents are particularly sensitive to the price of electricity, so electricity price forecasting is necessary.

\subsubsection{Load price elasticity}

The electicity price has the greatest influence on user behavior among the factors. The demand price elasticity is usually used to evaluate the influence of electricity price change on user response behavior, and load price elasticity is one of them (Wang, 2014). By predicting the response behavior of consumers to the electricity price, LA can more effectively evaluate the controllable capacity of consumers and formulate reasonable bidding schemes based on the prediction of the electricity price.
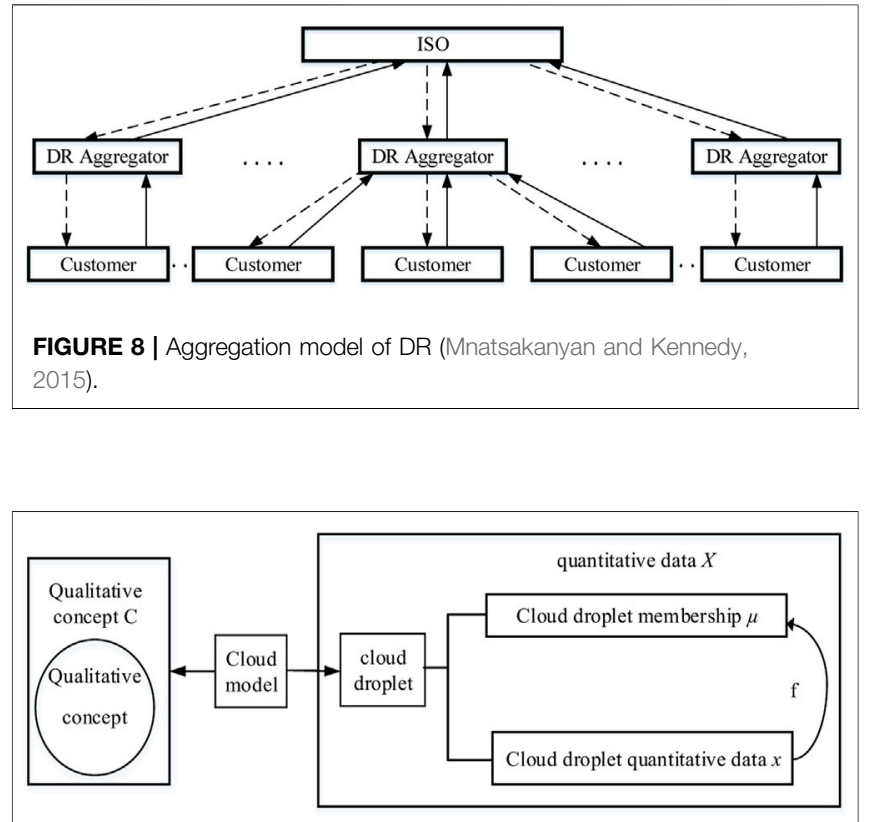

FIGURE 9 | Mapping diagram of the cloud model [63].

After the information prediction of demand-side resources, LA can integrate these demand-side resources to participate in the power market and obtain benefits, including the real-time market and day-ahead market of the main energy market, capacity market, and auxiliary service market, which can provide auxiliary services, such as rotary reserve, automatic generation control, and alternative reserve.

\subsection{Load integration method}

The optimal DR aggregation model for the whole power market is depicted in Figure 8 (Parvania et al., 2013). DR aggregators can be existing market participants (such as LA), which actively communicate with purchasers and customers of DR resources, such as ISO, to maximize DR. Examples of loads with large polymerization potential and flexible control are air conditioning and water heater.

\subsubsection{Air conditioning load}

Air conditioning load control methods can be divided into switch control, temperature control, and periodic suspension control. Considering the diversity of air conditioning load parameters, the aggregation method usually adopts secondary aggregation. In one 


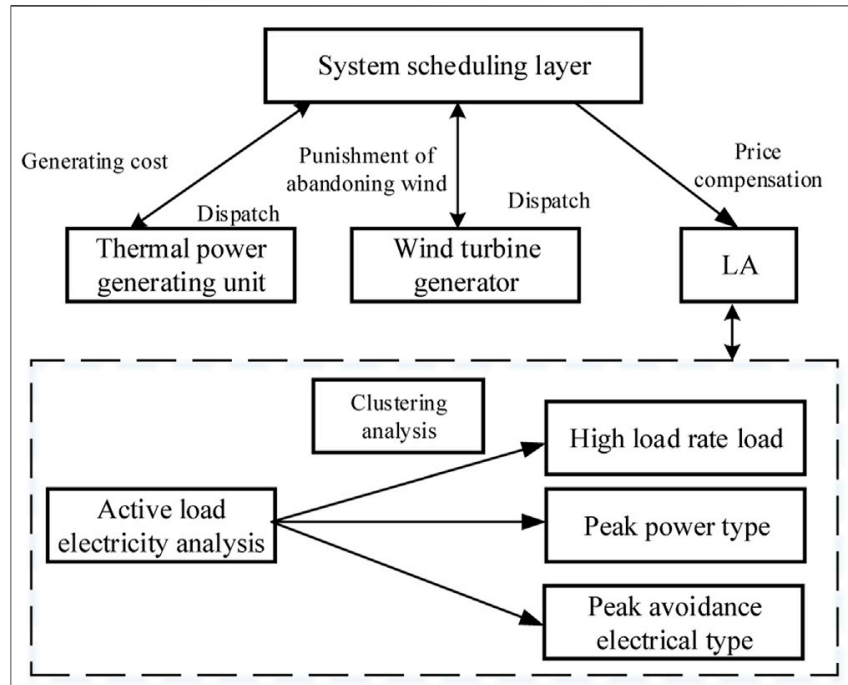

FIGURE 10 | Framework of the source-load interaction two-layer optimization model [66].

aggregation, air conditioners with similar parameters in the same area are divided into a group. Monte Carlo sampling, state queue, and state transition are used to analyze the switching state or power change of the air conditioning load group. The secondary polymerization is the load with different parameters in different regions, and the polymerization model is established through weighing other methods (Deng et al., 2015). Zhou et al. (2014) studied the influence of setting the value of temperature on load fluctuation for air conditioning load grouping with the same or similar parameters, and designed the upper and lower limit separation control method for air conditioning temperature based on the thermal parameter model, so that LA could aggregate largescale air conditioning load to participate in the DR market.

\subsubsection{Water heater load}

Water heater load is an energy storage load and also a high-quality DR load resource on the demand side. Its control methods include voltage control, temperature control, switch control, etc. (Liu et al., 2020). Ayoub (2013) proposed to realize the load of polymeric electric water heater based on voltage control, but additional physical hardware needs to be installed inside the water heater. Based on the hybrid logic dynamic model (temperature control), Sun et al. (2018) put forward situational awareness of water heater load to realize the absorption of new energy. Ning Lu (2013) proposed a load aggregation method based on switch control of temperature control equipment to provide a balanced standby service.

\subsection{Scheduling control strategy}

LA is able to aggregate demand-side resources. After information prediction, different scheduling control strategies can be developed according to the physical characteristics of different control resources. According to different purposes, it can be classified as follows:

\subsubsection{Improve the absorption rate of distributed generation}

LA proposes a load regulation algorithm based on the cloud model (as shown in Figure 9) that can realize the absorption of wind power through the integration of user group resources (Sun et al., 2017). Local consumption of distributed generation can be

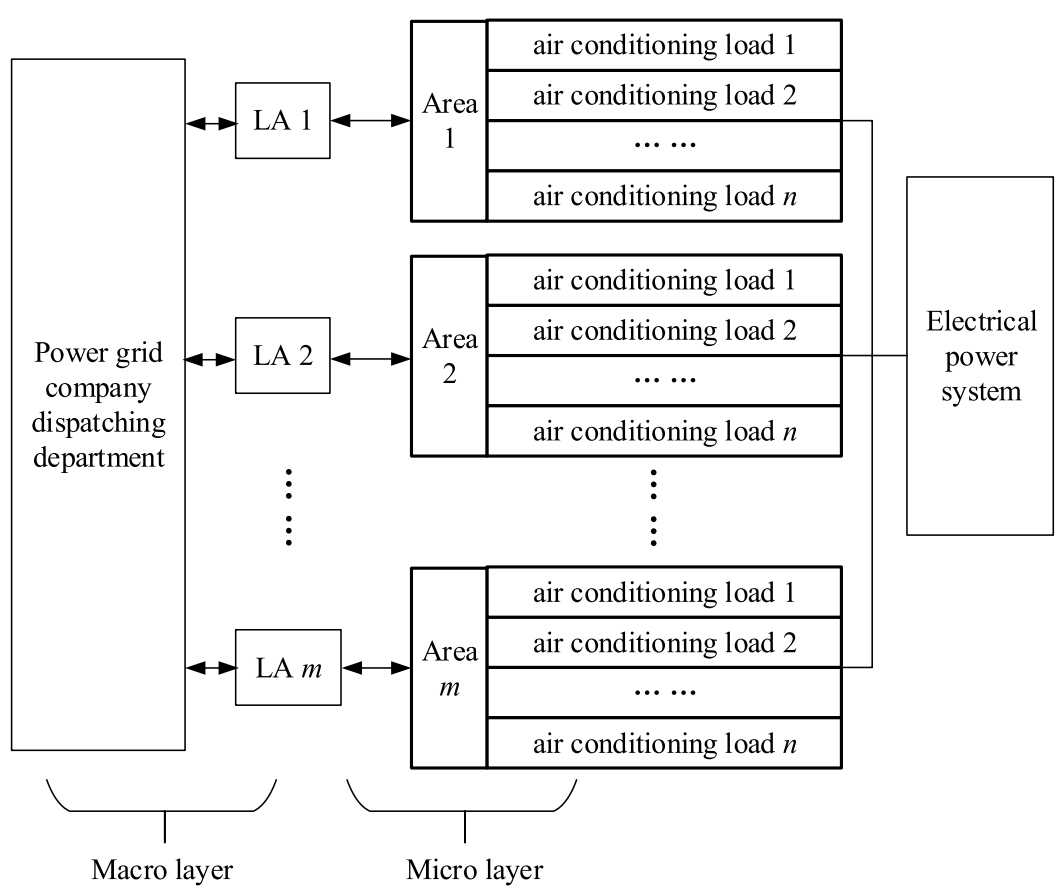

FIGURE 11 | Double-layer scheduling mode of air conditioning load. 


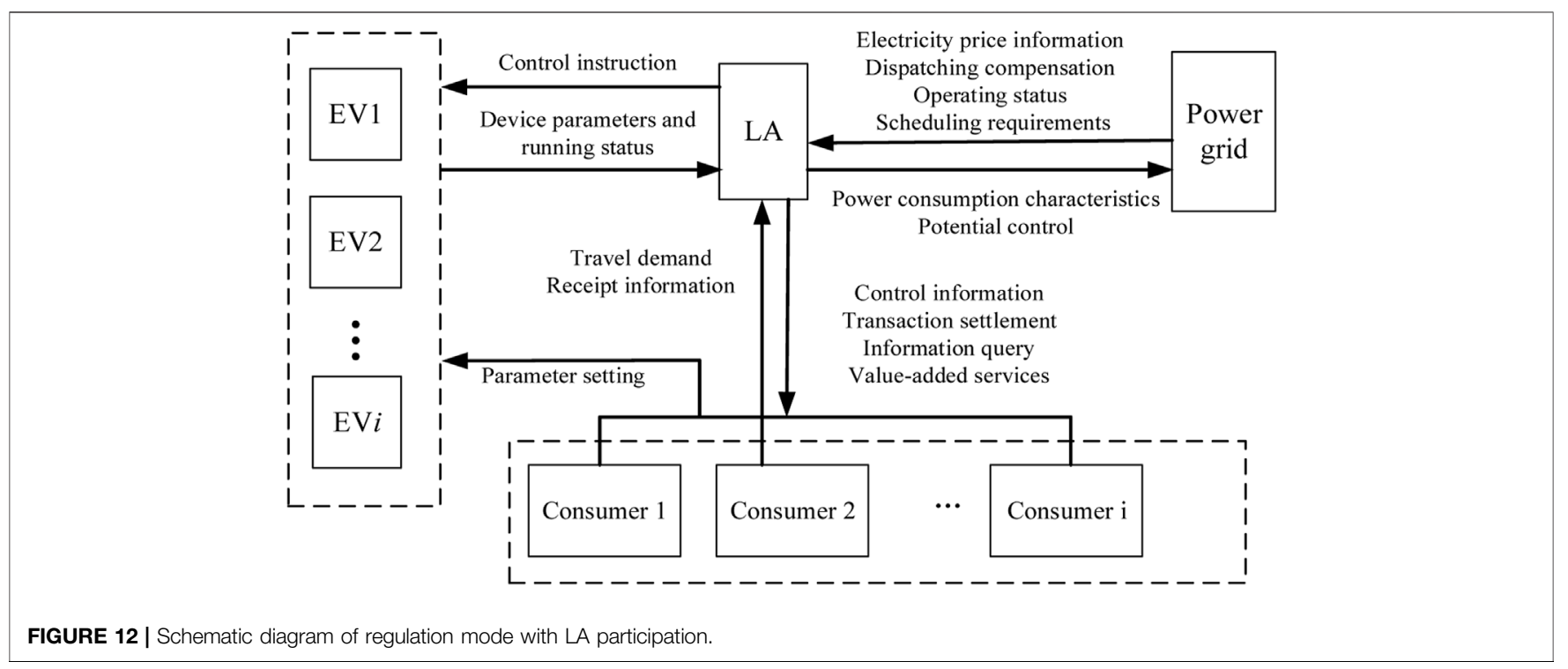

effectively achieved through hierarchical dispatch optimization that includes LA, residential, and microgrid (Cao et al., 2018).

\subsubsection{Improve the peak-valley difference}

LA can effectively dispatch residential loads and achieve load peak-to-valley differential by bidding decision optimization model through two DR contracts of load shedding and load shifting (Qi et al., 2018). LA participates in DR in the form of load reduction contract and builds an interactive two-layer optimization model of the source network. Its system framework diagram is shown in Figure 10, which can realize peak cutting and valley filling while taking into account the interests of all parties (Wen et al., 2017).

\subsubsection{Profit for demand response participants}

LA can maximize the profit of DR participation through a new DR scheme combined with fair billing mechanism (Mnatsakanyan and Kennedy, 2015). LA can maximize the power dispatching department and its own interests on the basis of coordinating user comfort and load adjustment space (Gao et al., 2014). The double-layer optimal scheduling of airconditioning load under direct load control is shown in Figure 11, and the decision makers of the macro- and microlayer models are the dispatching department and LA of power companies, respectively. The utilization of energy storage systems in LA can improve the reliability of power supply and reduce the risk of default, and the economic benefits of LA can be improved through the formulation of optimal scheduling strategy based on market hierarchical compensation rules (Zhang et al., 2015b).

\subsubsection{Participation in ancillary markets}

LA can integrate flexible load aggregation on the user-side into virtual energy storage, which together with the actual energy storage constitute the generalized energy storage to jointly provide power auxiliary services. The priority response strategy of virtual energy storage can improve the quality of auxiliary services and maximize the profits of LAs (Sun et al., 2020). LA can converge electric vehicles and participate in grid-assisted frequency regulation with the regulation mode as shown in Figure 12. Electric vehicles can respond quickly and accurately, improving the efficiency of frequency regulation and reducing power backup (Zhao, 2019).

\section{CONCLUSION}

\subsection{The conclusions are drawn as follows}

- In the initial stage of the construction of the China electricity market, the LA operation mode and decisionmaking model suitable for China national conditions still need to be further studied. Meanwhile, it is worth paying attention on how to formulate relevant DR plans according to the actual situation in the China electricity market.

- With the rise of distributed energy access and the gradual expansion of the scale of new electrical devices with energy storage attributes, such as electric vehicles, how LA is to effectively integrate more types of dispatchable resources is also the next research emphasis. The research work of applying EV energy storage to other auxiliary services, such as system backup, can be further developed.

- The bilateral uncertainty faced by LA still deserves attention, combining the market and user uncertainty on both sides of the study to be thoroughly studied. In addition, as the LA DR potential is enhanced and the network structure is expanded, the competition problem among LA clusters during control, and the spatial and temporal distribution of multi-LA loads, can be further considered to further explore and utilize the LA idle demand response potential.

\section{DATA AVAILABILITY STATEMENT}

The original contributions presented in the study are included in the article/Supplementary Material. Further inquiries can be directed to the corresponding author. 


\section{AUTHOR CONTRIBUTIONS}

ZP and YM proposed the concepts and ideas. MW analyzed the results. JY wrote the paper and revised the contents of the manuscript.

\section{REFERENCES}

Ayoub, S. (2013). "Electric Water Heaters Control Strategy for Providing Regulation Services and Load Leveling in Electric Power Systems," in 2013 IEEE Electrical Power and Energy Conference, Halifax, NS, Canada, 21-23 Aug. 2013, 1-6. doi:10.1109/EPEC.2013.6802972

Bandyopadhyay, A., Wang, L., Devabhaktuni, V. K., and Green, R. C. (2011). in 2011IEEE Power and Energy Society General Meeting, Detroit, MI, USA, 24-28 July 2011, 1-8. doi:10.1109/PES.2011.6039455

Burger, S., Chaves-Ávila, J. P., Batlle, C., and Pérez-Arriaga, I. J. (2017). A Review of the Value of Aggregators in Electricity Systems. Renew. Sustain. Energ. Rev. 77, 395-405. doi:10.1016/j.rser.2017.04.014

Cao, Y., Liu, J. F., and Gong, J. X. (2018). Optimization Model for Wind and Solar Power Accommodation Based on Load Aggregator. Renew. Energ. Resour. 36 (4), 563-567. doi:10.13941/j.cnki.21-1469/tk.2018.04.015

Chen, L., Yang, Y. B., Yao, J. G., Yang, S. C., Song, J., and Wang, B. B. (2013). Incentive Mechanism Design for Demand Response Based on Power Score. Electric Power Syst. Automation 37 (18), 82-87. doi:10.7500/AEPS201208245

Deng, Y. X., Wang, L., Li, Y., and Tian, J. (2015). Direct Load Control Strategies and Optimization Scheduling of Thermostatically Controlled Loads. Proc. CSUEPSA. 27 (6), 18-25. doi:10.3969/j.issn.1003-8930.2015.06.004

Dong, L., Chen, H., Pu, T. J., Chen, N. S., and Wang, X. H. (2016). Multi-time Scale Dynamic Optimal Dispatch in Active Distribution Network Based on Model Predictive Control. Proc. CSEE 36 (17), 4609-4617. doi:10.13334/j.02588013.pcsee. 151262

Gao, C. W., Li, Q. Y., Li, H. X., Zhai, H. B., and Zhang, L. (2013). Methodology and Operation Mechanism of Demand Response Resources Integration Based on Load Aggregator. Automation Electric Power Syst. 37 (17), 78-86. doi:10.7500/ AEPS201211091

Gao, C. W., Li, Q. Y., and Li, Y. (2014). Bi-level Optimal Dispatch and Control Strategy for Air-Conditioning Load Based on Direct Load Control. Proc. CSEE 34 (10), 1546-1555. doi:10.13334/j.0258-8013.pcsee.2014.10.005

Guo, Y. Z., Feng, B., Yue, B. X., Guo, C. X., Fan, J., and Jun, Y. S. (2021). Ultrashort-term Load Forecasting Considering Demand Response in Load Aggregator Mode. Automation Electric Power Syst. 45 (1), 79-87. doi:10.7500/AEPS20200330014

Jin, C. X., Xu, J., and Liao, S. Y. (2019). Coordination Strategy of Residential Demand Response Based on Smart Meter. Electr. Meas. Instrumentation 56 (13), 136147-137141. doi:10.19753/j.issn1001-1390.2019.013.023

Li, C. Y., Wang, D., Zhang, P., and Xie, K. G. (2017). Double Layer Real-Time Scheduling Model of Independent Microgrid Considering Scheduling Priority of Load Aggregators. Automation Electric Power Syst. 41 (06), 37-43. doi:10.7500/AEPS20160519004

Li, D. Y., Liu, C. Y., Du, Y., and Han, X. (2004). Artificial Intelligence with Uncertainty. J. Softw. 15(11), 1583-1594.

Li, T. J., Zhang, J., and Qi, B. (2015). Studies on Business Model of Demand Response for Residential Users. Power Grid Techn. 39 (10), 2719-2724. doi:10.13335/j.1000-3673.pst.2015.10.006

Liu, X. J., Zhou, X, J., Liu, D., Xie, X. Y., and Lu, Y. D. (2020). Refined Equilibrium Control of Electric Water Heater Clusters for Accommodation of Renewable Energy Sources. Electric power automation equipment 40 (1), 52-58. doi:10.16081/j.epae.202001003

Luo, H. H., Wang, H., Ge, W. C., Liu, C., and Wang, Y. B. (2021). Design of Dynamic Peak Regulation Ancillary Service Market Bidding Mechanism Considering Quotation Supervision. Trans. China Electrotechnical Soc. 36 (9), 1935-1947. doi:10.19595/j.cnki.1000-6753.tces.200264

Mnatsakanyan, A., and Kennedy, S. W. (2015). A Novel Demand Response Model with an Application for a Virtual Power Plant. IEEE Trans. Smart Grid 6 (1), 230-237. doi:10.1109/TSG.2014.2339213

\section{FUNDING}

This work is financially supported by the Jiangsu Electric Power Company Research Foundation under grant. no. SGJS0000YXJS2001039.

Ning Lu, L. (2013). “Design Considerations of a Centralized Load Controller Using Thermostatically Controlled Appliances for Continuous Regulation Reserves," in 2013 IEEE Power and Energy Society General Meeting, Vancouver, BC, July 21-25, 2013, 1. doi:10.1109/PESMG.2013.6672203

Parvania, M., Fotuhi-Firuzabad, M., and Shahidehpour, M. (2013). Optimal Demand Response Aggregation in Wholesale Electricity Markets. IEEE Trans. Smart Grid 4 (4), 1957-1965. doi:10.1109/TSG.2013.2257894

Peng, X. S., Xiong, L., Wen, J. Y., Cheng, S. J., Deng, D. Y., Feng, D. Y., et al. (2016). A Summary of the State of the Art for Short-Term and Ultra-short-term Wind Power Prediction of Regions. Proc. CSEE 36 (23), 6315-6326. doi:10.13334/ j.0258-8013.pcsee.161167

Qi, N., Cheng, L., Tian, L. T., Guo, J. B., Huang, R. L., and Wang, C. P. (2020). Review and Prospect of Distribution Network Planning Research Considering Access of Flexible Load. Automation Electric Power Syst. 44 (10), 193-207. doi:10.7500/AEPS20191030003

Qi, X. J., Cheng, Q., Wu, H. B., Yang, S. H., and Li, Z. X. (2018). Impact of Incentive-Based Demand Response on Opreational Reliability of Distribution Network. Trans. China Electrotechnical Soc. 33 (22), 5319-5326. doi:10.19595/ j.cnki.1000-6753.tces.171376

Qian, J. H. (2019). Research on Optimal Scheduling and Operation Strategy of Load Aggregators in Electricity Market. Changsha: Changsha University of Science and Technology.

Saad, Y. E.-M., Salama, M. M. A., Elshatshat, R. A., and Ponnambalam, K. (2009). "The Operation of a Distribution Company under Uncertainty: An Overview," in 2009 IEEE Power and Energy Society General Meeting, Calgary, AB, July 26-30, 2009., 1-7. doi:10.1109/PES.2009.5275857

Shu, Y. B., Xue, Y. S., Cai, B., Ling, W., Han, J. G., Chen, X. Y., et al. (2018). A Review of Energy Transition Analysis Part Two Uncertainties and Approaches. Automation Electric Power Syst. 42 (10), 1-12. doi:10.7500/AEPS20180417009

Shu, Y. B., Zhang, Z. G., Guo, J. B., and Zhang, Z. L. (2017). Study on Key Factors and Solution of Renewable Energy Accommodation. Proc. CSEE 37 (1), 1-9. doi:10.13334/j.0258-8013.pcsee.162555

Sun, Q., Jiang, R., Zheng, Z., Zhong, L., Chen, S., Wang, F., et al. (2022). Effect of Extended Grading Capacitor on the Interrupting Performance of Multi-Break Circuit Breaker during Out-of-step Faults. Int. J. Electr. Power Energ. Syst. 136, 107616. doi:10.1016/j.ijepes.2021.107616

Sun, W. J., Xiang, W., Pei, L., Li, H. Z., and Xi, P. F. (2020). Generalized Energy Storage Control Strategies on User Side in Power Ancillary Service Market. Automation Electric Power Syst. 44 (2), 68-76. doi:10.7500/AEPS20190522003

Sun, Y., Shi, M., Xu, P., Li, B., and Yang, B. (2018). Situation Awareness and Control Strategy of Water Heater Group Based on Mixed Logical Dynamic Model. Proc. CSEE 38 (17), 5043-5051. doi:10.13334/j.0258-8013.pcsee.172016

Sun, Y., Yang, Y. M., Xu, P., Li, B., Chen, S. S., and Cui, G. Y. (2017). A User Group Load Control Algorithm Based on Cloud Model. Power Syst. Techn. 41 (8), 2611-2617. doi:10.13335/j.1000-3673.pst.2016.2772

Tabandeh, A., Abdollahi, A., and Rashidinejad, M. (2016). Reliability Constrained Congestion Management with Uncertain Negawatt Demand Response Firms Considering Repairable Advanced Metering Infrastructures. Energy 104, 213-228. doi:10.1016/j.energy.2016.03.118

Wang, B. B. (2014). Research on Consumers' Response Characterics and Ability under Smart Grid: a Literatures Survey. Proc. CSEE 34 (22), 3654-3663. doi:10.13334/j.0258-8013.pcsee.2014.22.010

Wei, Z. L., Yu, S., Sun, G. Q., Sun, Y. H., and Wang, D. (2013). Review on European Research Projects of Virtual Power Plan. Automation Electric Power Syst. 37 (21), 196-202. doi:10.7500/AEPS20130513006

Wen, G., Weng, W. H., Zhao, Y., and Jiang, C. H. (2017). A Bi-level Optimal Dispatching Model Considering Source-Load Interaction Integrated with Load Aggregator. Power Syst. Techn. 41 (12), 3956-3963. doi:10.13335/j.10003673.pst.2017.0491 
Wu, Y. B., Li, J. E., Chen, X., Liu, Q. Y., Wang, Y., Luo, J. B., et al. (2018). Risk Analysis of Distribution Network with Large-Scale Controllable Loads with Attacks. Automation Electric Power Syst. 42 (10), 30-37. doi:10.7500/ AEPS20171026017

Zeng, M., Yang, Y. Q., Liu, D. N., Zeng, D. N., Ouyang, S. J., Lin, H. Y., et al. (2016). "Generation-Grid-Load-Storage" Coordinative Optimal Operation Mode of Energy Internet and Key Technologies. Power Syst. Techn. 40 (1), 114-124. doi:10.13335/j.1000-3673.pst.2016.01.016

Zhang, K. Y. (2015). Research on Market Based Decision-Making for Load Aggregators under Smart Grid Environment. Shanghai: Shanghai Jiao Tong University.

Zhang, K. Y., Song, Y. Q., and Yan, Z. (2015a). Energy Storage Capacity Optimization for Load Aggregators Considering Probability of Demand Response Resources' Breach. Automation Electric Power Syst. 39 (17), 127-133. doi:10.7500/AEPS20150203009

Zhang, K. Y., Song, Y. Q., Yan, Z., Yang, L. B., and Hong, Y. R. (2015b). Research on Bidirectional Decision-Making for Load Aggregators Participating in Market Transactions and Dispatching Adjustable Loads. Water Resour. Power 33 (9), 209-212.

Zhang, P. (2019). Research on Operation Strategy and Risk of Load Aggregator Considering Uncertainty. Hefei: Hefei University of Technology.

Zhang, Z. S., and Yu, D. Y. (2018). RBF-NN Based Short-Term Load Forecasting Model Considering Comprehensive Factors Affecting Demand Response. Proc. CSEE 38 (6), 1631-1638. doi:10.13334/j.0258-8013.pcsee.170835

Zhao, H., and Liu, R. (2017). Benefit Analysis of Optimal Schedule of Virtual Power Plant under Reward-Punishment Mechanism. Power Syst. Techn. 41 (9), 2840-2847. doi:10.13335/j.1000-3673.pst.2017.0907

Zhao, P. F. (2016). Demand Response Incentive Mechanism Design of Civil Load with Distributed Sources \& Energy Storage. Beijing: North China Electric Power University.
Zhao, Y. J (2019). Research on the Regulation Strategy of Electric Vehicle Aggregators Participating in Power Grid Ancillary Services. Beijing: North China Electric Power University.

Zhou, L., Li, Y., and Gao, C. W. (2014). Improvement of Temperature Adjusting Method for Aggregated Air-Conditioning Loads and its Control Strategy. Proc. CSEE 34 (31), 5579-5589. doi:10.13334/j.02588013.pcsee.2014.31.015

Conflict of Interest: ZP was employed by the State Grid Jiangsu Electric Power Co. Ltd. Yancheng Power Supply branch. YM was employed by the State Grid Jiangsu Electric Power Co. Ltd. MW was employed by the Grid Jiangsu Electric Power Co. Ltd. Wuxi Power Supply branch.

The remaining author declares that the research was conducted in the absence of any commercial or financial relationships that could be construed as a potential conflict of interest

Publisher's Note: All claims expressed in this article are solely those of the authors and do not necessarily represent those of their affiliated organizations, or those of the publisher, the editors, and the reviewers. Any product that may be evaluated in this article, or claim that may be made by its manufacturer, is not guaranteed or endorsed by the publisher.

Copyright $(2021 \mathrm{Pei}, \mathrm{Ma}, \mathrm{Wu}$ and Yang. This is an open-access article distributed under the terms of the Creative Commons Attribution License (CC BY). The use, distribution or reproduction in other forums is permitted, provided the original author(s) and the copyright owner(s) are credited and that the original publication in this journal is cited, in accordance with accepted academic practice. No use, distribution or reproduction is permitted which does not comply with these terms. 